\title{
For A South-Relevant Psychometric
}

\author{
Anne Fromont ${ }^{1 *}$, Isabelle Godin ${ }^{1}$, Elias Mpofu² and Annalisa Casini ${ }^{3}$ \\ ${ }^{1}$ Université Libre de Bruxelles, Belgium \\ ${ }^{2}$ University of Sidney, Australia \\ ${ }^{3}$ Université catholique de Louvain, Belgium
}

*Corresponding author: Anne Fromont, School of Public Health, Université Libre de Bruxelles, Belgium, Tel: +32 2555 4084; Email: fromont.anne@gmail.com

Submission: 望 June 26, 2018; Published: 拝 July 05, 2018

\section{Introduction}

In our globalised world, the contribution of social sciences is crucial, particularly with regard to the challenges of our time. Migrations, transnational undertakings, international issues health and environment related are major concerns that require shared perspectives. We can no longer afford former and standardized responses. Our generation smartly need a deeper understanding of diverse realities. The construction and the dissemination of cross-cultural knowledge's are essential in order to break through received ideas and misconceptions. Majority and minority world traditions in the psychological sciences. Science is a tool into the hands of the ruling classes who ask questions, determine objects of study and choose attractive notions [1].

In that respect, the mainstream psychology inherited a double cultural halo effect, at the expense of "minorities" (or the dominated groups, who actually represent the majority) [2]. First, from an intercultural point of view, the global preponderance of western culture tend to present western school of thinking as "natural" and universal [3-5]. This ethnocentric vision is consistent with colonialist history of the 19-20th century. Thus, most of scientific theories -not only in psychology, but in social and human sciences at large- assume an individualistic point of view where individual factors explain behaviour [6]. Yet, in most cultures, the sense of self is mostly nested in the relationship with the social and the metaphysical environment [7-10].

Secondly, from an intracultural point of view, studies are mainly conducted with sampled from WEIRD (white, educated, industrialized, rich, developed) countries, typically with young, educated and white individuals, from which results are generalized to the global population [11]. Historically, this western approach occurred when psychology claimed the status of exact science, developing a positivist vision relying on validated concepts and instruments. Wilhelm Wundt (1832-1920), the founder of the first pioneering psychological laboratory in Leipzig in 1879, laid the first stone of a "genuinely empirical" psychology, physiology-related but purposely completely disconnected from the social reality $[12,13]$. Marking a shift from general to applied psychology, but still relying on the same empirical standpoint, William Stern (1871-1938) introduced the notion of intelligence quotient and coined the term "psycho-technical" to refer to "a technical science, related to causal psychology as engineering is related to physics" (Miinsterberg 1914, cited in [14]). His work did not explore the social structuration but, rather posed the "national nature" as immutable and definitely established [1]. For instance, the intelligence tests do not consider the environmental impact of formation and learning. The plasticity of human nature, the structuration through environment, the lability of psychological trait was denied [1].

Emics and Etics in Psychological Conceptions and Misconceptions

Several methodological issues raise questions about the interpretation of results in such a perspective. First, the reliability and the validity of psychometric tests are not consistently guaranteed $[4,15]$. At the most basic level, the forms of the measures used to collect quantitative data pertaining to psychological issues are not universally applicable. For instance, the use of Likert-type scales, conceptual categories, negatively worded sentences are inadequate in many contexts and situations $[9,16,17]$. The chosen words, in and of themselves, implies cultural context mainly through the semantics of each specific language paradigm. Further, some constructs or categories are not always valid. Among many examples, the RSES [7], the WIAS-III [18], the mental retardation at a particular point in time [19] are often discussed, and criticized, in the cross-cultural perspective. Secondly, the use of improper tools leads to inappropriate operational decisions.

The use of work and organisational psychology concepts for managing decisions is another strong example. The psychotechnical movement reflects a perspective on scoring that is not a scientific one. It has an evaluative goal but not a real understanding purpose [20]. Psycho-technic tools are tested in laboratory, without validation in professional practice settings, and thereby by ignoring the effect of the social environment. Subsequently, work organisations adopted psycho-technic practices since the 1950's by using personality for measuring psychological indicators, as 
performance, motivation or satisfaction at work, with no validation by cultural background. These diagnoses was assumed since the middle of XXth century [21,22] but do not consistently result in the development of adapted and validated tools supported by a robust theoretical current. In some settings, local measure validation efforts resulted with a poorly normed instruments with little evidence for validity and the reliability $[23,24]$.

\section{Implications for International Psychological Science Development}

Several initiatives called for the formation of an international psychology institute in response to cultural diversity or for the development of indigenous psychology [25-27]. Yet, the development and use of specific and robust tools is still a challenge and calls us to reflect on it. We first have to question our own knowledge and our internalisation of ethnocentrism as well as to sort out the confusion between westernization and modernization [4]. Researchers have also to disclose the limits of the measurement tools and their use by adding a real understanding of underlying theories and constructs.

Further, we need to engage in a true dialogue between and within cultures, from the individual to the international levels, and highlight the advocacy to promote contextualised and evidencebased practices. But all these goals are not attainable if we cannot guarantee the development of a fundamental and locally rooted research. Indeed, fundamental research is underfunded in many, so called, developing countries. Indeed, in Africa or in South America, researchers and practitioners, trained in Western universities, in a colonial model of education, have little choice. Few funders support fundamental research and the most of them are oriented by operational considerations. This situation contributes to perpetuate unequal relationship between North and South by hiding realities. Social issues need to be addressed by considering the human variability and wealth. We still need tools and theories to think our world and to discover unknown areas. For this, fundamental non-western-ethnocentred research has never been so fundamental. Donors, politics, researchers and fields actors must face and embrace this issue.

\section{References}

1. Spielrein I (2012) De la théorie de la psychotechnique. Bulletin de psychologie 3(519): 283-295.

2. Kağıtçıbaşı Ç (2007) Family, self and human development across cultures: Theory and applications. $\left(2^{\text {nd }}\right.$ edn), Erlbaum, New Jersey, USA.

3. Sánchez-Sosa JJ, Riveros A (2007) Theory, Research, and Practice in Psychology in the Developing (Majority) World. In: Dans M Stevens \& U Gielen (Eds.), Toward a global psychology: Theory, research, intervention and Pedagogy. Lawrence Erlbaum associates, London, UK, pp. 101-146.

4. Mpofu E (2002) Psychology in sub-Saharan Africa: Challenges, prospects and promises. International Journal of Psychology 37(3): 179-186.

5. Azuma H (1984) Psychology in a non-Western country. International Journal of Psychology 19(4): 45-55.

6. Green J (1999) Cultural awareness in the human services: A multi-ethnic approach. (3 $3^{\text {rd }}$ dn), Allyn \& Bacon.
7. Fromont A, Haddad S, Heinmüller R, Dujardin B, Casini A (2017) Exploring the validity of scores from the Rosenberg Self-Esteem Scale (RSES) in Burundi: A multi-strategy approach. Journal of Psychology in Africa 27(4): 316-324.

8. Mboya M (1999) Culture and self from an African perspective. Pretoria, Ilitha, South Africa.

9. Mpofu E (1994) Exploring the self-concept in an African culture. Journal of Genetic Psychology 155(3): 341-354.

10. Triandis H, Betancourt H, Iwao S, Leung K, Salazar JM, et al. (1993) An ETIC-EMIC analysis of individualism and collectivism. Journal of CrossCultural Psychology 24(3): 366-383.

11. Henrich J, Heine S, Norenzayan A (2010) The weirdest people in the world? Behavioral and brain science 33(2-3): 61-135.

12. Toulmin S, Leary D (1985) The cult of empiricism in psychology, and beyond. In: Dans S Kock \& D Leary (Eds.), A Century of Psychology as Science. McGraw-Hill, New York, pp. 594-617.

13. Farr R (1983) Wilhelm Wundt (1832-1920) and the origins of psychology as an experimental and social science. British Journal of Social Psychology 22(4): 289-301.

14.Van Strien P (1998) Early applied psychology between essentialism and pragmatism: The dynamics of theory, tools, and clients. History of Psychology 1(3): 205-234.

15. Sayed Y, Kanjee A (2013) Assessment in Sub-Saharan Africa: challenges and prospects. Assessment in Education: Principles, Policy \& Practice 20(4): 373-438.

16. Distefano C, Motl R (2006) Further investigating method effects associated with negatively worded items on self-report survey. Structural Equation Modeling: A Multidisciplinary Journal 13(3): 440-464.

17. Suh E, Diener E, Oishi S, Triandis H (1998) The Shifting Basis of Life Satisfaction Judgments Across Cultures: Emotions Versus Norms. Journa of Personality and Social Psychology 74(2): 482-493.

18. Foxcroft CD, Aston S (2006) Critically examining language bias in the south african adaptation of the WAIS-III. Journal of Industrial Psychology 32(4): 97-102.

19. Jenkins R (1998) Culture, classification and (in) competence. In: Dans JR (Ed.), Questions of competence. Cambridge University Press, Cambridge, UK, p. 1-24.

20. Vautier S (2015) La psychotechnique des aptitudes. Pour différencier unesociotechnique de l'évaluation sans mesurage et une psychologie balbutiante de la compréhension de la performance. Pratiques psychologiques 21: 1-18.

21. Robaye F (1960) Principes pour l'aménagement des épreuves psychotechniques utilisées avec des noirs congolais. Le travail Humain 23(1/2): 93-96.

22. Davidson A, Jaccard J, Triandis H, Morales M, Diaz-Guerrera R (1976) Cross-cultural model testing: toward a solution of the etic-emic dilemma. International Journal of Psychology 11(1): 1-13.

23. Van Ommeren M (2003) Validity issues in transcultural epidemiology. British Journal of Psychiatry 182(5): 376-378.

24. Larouche R, Oyeyemi AL, Prista A, Onywera V, Akinroye KK (2014) A systematic review of active transportation research in Africa and the psychometric properties of measurement tools for children and youth. International Journal of Behavioral Nutrition and Physical Activity 11: 129.

25. Adamopoulos J, Lonner WJ (2001) Culture and psychology at a crossroad: Historical perspective and theoretical analysis. In: Dans D Matsumoto (Ed.), Handbook of culture and psychology, Oxford University Press, New York, USA, p. 11-34 
26. Mpofu E, Zindi F, Oakland T, Peresuh M (1997) School psychological practices in East and Southern Africa. Journal of special education 31(3): 387-402.
27. The Working Group on the Development of the African Psychological Association/Society (2000) Minutes of Inaugural Meeting. Stockholm, Sweden.
PPRS Psychology and Psychotherapy:
Research Study International License

\section{Psychol Psychother Res Stud \\ Benefits of Publishing with us}

- High-level peer review and editorial services

- Freely accessible online immediately upon publication

- Authors retain the copyright to their work

- Licensing it under a Creative Commons license

- Visibility through different online platforms 